\title{
Penggunaan Metode Ontology Untuk Perancangan Purwarupa Sistem Smart Home Berbasis Context Aware
}

\author{
Guntur Perdana*1, Ahmad Ashari ${ }^{2}$ \\ ${ }^{1}$ Prodi Elektronika dan Instrumentasi, FMIPA UGM, Yogyakarta, Indonesia \\ ${ }^{2}$ Departemen Ilmu Komputer dan Elektronika, FMIPA UGM, Yogyakarta, Indonesia \\ e-mail: *1 ${ }^{1}$ untur.perdana@ugm.ac.id, ${ }^{2}$ ashari@ugm.ac.id
}

\begin{abstract}
Abstrak
Sistem smart home adalah sebuah sistem berbantuan komputer yang akan memberikan segala kenyamanan, keselamatan, keamanan dan penghematan energi, yang bekerja secara otomatis dan terprogram melalui komputer pada gedung atau rumah. Salah satu metode yang dapat digunakan untuk merancang smart home adalah dengan menggunakan metode context aware. Context aware dapat bekerja dengan bantuan beberapa metode yang lain seperti salah satunya adalah metode ontology.

Ontology memiliki beragam pengertian dan selalu mengalami perubahan sesuai dengan berjalannya waktu selalu ada definisi dari ontology. Metode ontology adalah salah satu metode yang dapat mengolah data-data yang kompleks. Metode ontology memungkinkan penalaran dan representasi yang kompleks dengan hasil yang lebih baik. Kendala yang sering dihadapi ketika melakukan perancangan sebuah sistem yang terlihat kompleks akan menghadapi banyak permasalahan pada domain seperti banyaknya domain yang bersifat ambiguitas.

Keberadaan rancangan ontology terlebih dahulu sebelum melakukan perancangan purwarupa sistem smart home akan mempermudah proses perancangan smart home terlebih jika sistem yang akan dibuat lebih kompleks sehingga memungkinkan adanya ambigu dari beberapa domain. Pengujian dengan metode ontology ini cukup efektif untuk meminimalisir ambigu dari setiap domain, karena setiap domain dirancangan dengan memiliki ciri yang berbeda. Hasil dari pengujian tersebut menyimpukan bahwa rancangan ontology dapat diwujudkan menjadi purwarupa sistem smart home.
\end{abstract}

Kata Kunci-smart home, context, ontology

Smart home system is a computer-aided system that will provide all comfort, safety, security and energy savings, which works automatically and programmed through a computer in a building or home. One of the method that can be used to design smart home is context aware method. Context aware can work with the help of several other methods such as ontology method.

Ontology has a variety of definition and always changes time by time. Ontology method is one of method that can process complex data. The ontology method allows complex reasoning and representation with better results. Constraints that are often encountered when designing a system that looks complex will face many problems such as many ambiguous domains.

The existence of an ontology design before carrying out the prototype design of the smart home system will facilitate the smart home design process especially if the system will be made more complex so it would allows ambiguity from multiple domains. Testing with this ontology method is effective enough to minimize ambiguity from each domain, because each domain is designed with different characteristics. The results of the test concluded that the ontology design can be realized as a prototype of the smart home system.

Keywords - smart home, context, ontology

Received September $24^{\text {th }}, 2018 ;$ Revised April 10 ${ }^{\text {th }}, 2019 ;$ Accepted October $31^{\text {th }}, 2019$ 


\section{PENDAHULUAN}

Teknologi context aware merupakan salah satu teknologi yang dapat diimplementasikan pada aplikasi pintar. Salah satu aplikasi pintar yang dapat menggunakan konsep context aware adalah smart home. Smart home adalah sebuah konsep cerdas yang memanfaatkan teknologi secara maksimal, dengan kontrol terpusat untuk mengendalikan efesiensi, kenyamanan dan keamanan [1].

Context aware menawarkan sistem yang dapat merasakan dan bereaksi terhadap lingkungannya. Sistem tersebut memiliki informasi tentang keadaan yang memungkinkan untuk beradaptasi dan beroperasi berdasarkan pengaturan yang telah ditetapkan. Dengan begitu, sistem pada smart home dapat beradaptasi dengan sendirinya tanpa harus dilakukan perubahan pengaturan. Dan sistem juga dapat bekerja secara terus-menerus sesuai dengan keinginan dari pengguna

Penggunaan dari context aware sendiri menggunakan banyak informasi dari suatu keadaan atau kondisi tertentu, sehingga terdapat kesulitan dalam pengolahan data pada sistem tersebut. Supaya data dapat diolah dengan baik maka diperlukan suatu metode yang dapat mengolah data-data yang kompleks menjadi output seperti yang diinginkan dan sistem dapat bekerja secara maksimal. Ada banyak metode yang dapat digunakan untuk membantu context aware salah satunya adalah metode ontology.

Metode ontology adalah salah satu metode yang dapat mengolah data-data yang kompleks menjadi lebih mudah. Metode ontology memungkinkan penalaran dan representasi yang kompleks dengan hasil yang lebih baik. Dengan demikian ontologi dalam ilmu komputer adalah cara untuk merepresentasikan suatu domain pengetahuan secara eksplisit mengenai suatu konsep dengan cara memberikan makna, properti, serta relasi pada konsep tersebut sehingga terhimpun dalam suatu domain pengetahuan dan membentuk sebuah basis pengetahuan (knowledge base)[2]. Ontology banyak diterapkan oleh banyak peneliti untuk melakukan berbagai macam riset atau penilitian Maka jika metode ontology digunakan pada sistem smart home akan membuat sistem yang bekerja lebih efisien terlebih lagi dengan digunakannya context aware akan membantu kinerja dari smart home. Penggunaan dari context aware yang membutuhkan context yang kompleks akan dapat teratasi dengan menggunakan metode ontology, karena metode ontology sendiri dapat mengerjakan data yang kompleks sehingga dapat dihasilkan output yang sesuai dengan yang diinginkan.

\section{METODE PENELITIAN}

\subsection{Analisis sistem}

Metode Ontology digunakan untuk sistem smart home pada umumnya agar mempermudah ataupun membantu kinerja dari sistem. Dimana kerja dari metode Ontology pada sistem smart home digunakan untuk membantu kinerja dari context aware dengan sensor-sensor yang di jadikan sebagai context nya. Pengertian dari context adalah segala informasi yang dapat digunakan sebagai identitas atau sesuatu yang memang sungguh ada (manusia, tempat atau objek) dengan mempertimbangkan interaksi yang relevan antara pengguna dan aplikasi [3]. Dari penjelasan yang diberikan Zhao dan Lü context bisa berupa banyak hal yaitu segala informasi yang dapat dijadikan sebagai identitas maupun segala sesuatu yang memang sungguh ada sehingga dapat dijadikan sebagai acuan untuk suatu aplikasi. Sedangkan context aware membantu orang-orang untuk dapat beradaptasi dengan kondisi baru secara terus-menerus. Context aware adalah kemampuan untuk merasa dari situasi pengguna dari segala kondisi dan beradaptasi dari segala konsekuensi perilaku sistem [4].

Penggunaan dari context aware sangat luas dapat digunakan dalam berbagai bidang seperti salah satunya adalah smart home. Penggunanaan pada smart home ditujukan untuk menunjang kinerja dari sistem agar sistem dapat bekerja secara maksimal dengan memanfaatkan 
identitas atau segala sesuatu informasi yang miliki atau dapat menjadi identitas seperti ciri dari pengguna, tempat atau lokasi dan objek yang dapat dibaca melalui sensor.

Pada penelitian ini context yang digunakan adalah nilai bacaan yang di identifikasi sebagai identitas dari objek yang dibaca oleh sensor tersebut. Sensor akan terhubung dengan mikrokontroler yang akan mengendalikan sensor-sensor tersebut. Sensor yang digunakan pada sistem smart home ini adalah:

- Sensor ultrasonik untuk membaca data jarak dari pengguna ketika datang mendekati rumah.

- Sensor Passive Infrared Receiver (PIR) untuk membaca data pergerakan dari pengguna.

- Sensor Force Sensitive Resistor (FSR) untuk membaca data tekanan yang diberikan oleh pengguna.

Data yang diterima dari sensor-sensor tersebut oleh mikrokontroler akan di lanjutakan menuju raspberry pi untuk selanjutnya akan diproses. Pada fase ketika data berada pada raspberry pi agar data dan sistem yang terdapat pada smart home tidak berantakan dan ambigu maka digunakan metode ontologi. Ontologi digunakan agar data yang dihasilkan dan sistem yang ada dapat tersusun dengan rapi dan sistem dapat menjadi lebih terstruktur [5]. Penyusunan sistem berdasarkan pada kategori perangkat yang saling memiliki hubungan satu dengan perangkat yang lainnya. Jadi maksut dari metode ini adalah untuk membagi tiap perangkat yang masing-masing nya saling memiliki hubugan satu dengan yang lainnya kedalam tiap-tiap kelompok yang dibagi sesuai dengan fungsi yang sama tanpa terlepas dari hubungan satu dengan yang lainnya [6].

\subsection{Perancangan ontology}

Rancangan ontology dibuat agar sistem bekerja sesuai dengan porsinya atau lebih memaksimalkan kerja dari sistem. Perancangan menggunakan OWL (Ontology Web Language) ditujukan agar sistem yang dibuat memiliki entitas yang jelas pada setiap bagian dari sistem tersebut. Perancangan dengan $O W L$ ditujukan untuk melakukan klasifikasi konteks apakah sudah sesuai dengan yang semestinya. Digunakannya metode ontology pada pembuatan sistem smarthome ini dapat juga mempermudah dalam menentukan tujuan dari setiap perangkat yang digunakan pada rancangan sistemnya. Penelitian ini menggunakan context sebagai fokus utamanya untuk smarthome maka untuk menjalankan sistem tersebut perlu dibntu dengan metode ontology karena dengan digunakannya metode ini menjadikan penggunaan dari context aware dapat diterapkan dan lebih diperjelas lagi dari setiap context-nya.

Perancangan sistem dengan penerapan ontology dapat dilakukan dengan melibatkan dua hal utama yaitu bahasa dan software. Bahasa ontology dapat dibedakan menjadi dua, yaitu konvensional dan web-based. Untuk penelitian ini menggunakan bahasa ontology yang berasal dari web-based yaitu bahasa OWL (Ontology Web Language) akan tetapi untuk penerapannya digunakan secara konvensional yang dimaksudkan tidak digunakan secara langsung pada web tetapi pada sistem kerja dengan sistem offline. Software untuk membangun ontology juga ada bermacam-macam seperti OntoEdit, WebODE, Altova, Ontorion dan Protégé. Dari semua software yang telah disebutkan Protégé merupakan software yang banyak digunakan baik dalam penelitian maupun untuk pengembangan aplikasi ontology, maka dari itu software yang digunakan untuk merancang ontology pada penelitian ini adalah Protégé. Beberapa elemen yang harus dimiliki agar dapat disebut sebagai ontology yaitu[7]:

1. Instance

Instance atau bisa disebut juga dengan individual yang merupakan anggota dari classes. Instance dapat dilihat sebagai objek ynag ada pada domain yang dibahas. Instance sendiri tidak memiliki definisi dari relasi satu dengan lainnya.

\section{Property}

Property itu ada dua jenisnya pada ontology web semantik, yaitu object dan datatype property. Object property fungsi nya adalah untuk menghubungkan anatar ibjek satu dengan objek yang lainnya sedangkan datatype property digunakan untuk menghubungkan antara objek dengan datatype value seperti contohnya text, string atau number.

Penggunaan Metode Ontology untuk Perancangan Purwarupa Sistem ... (Guntur Perdana) 
3. Class

Class adalah titik pusat dari ontology. Menjelaskan tentang konsep pada suatu domain yang terdiri dari beberapa instance atau individual. Dikenal juga sebagai concept, objecy dan categories. Sebuah class memiliki subclass yang ditujukan untuk menyatkan concept lebih spesifik dari superclass.

\subsection{Arsitektur sistem}

Rancangan purwarupa sistem smart home dari penelitian ini dibutuhkan rancangan perangkat lunak dan perangkat keras. Perangkat keras digunakan sebagai penggambaran dari bentuk rumah dengan membuat sebuah miniatur rumah menggunakan bahan dari akrilik yang dibentuk sedemikian rupa sehingga dapat mewakili bentuk dari rumah yang sesungguhnya. Dengan 3 buah ruangan sebagai penggambaran dari ruangan pada rumah dengan ukuran yang sebenarnya, sedangkan rancangan elektronik disesuaikan dengan kebutuhan sistem.

Hasil baca data sensor diperoleh posisi dari pengguna bergerak mendekati rumah dan hasil baca suhu dan kelembapan dari ruangan kemudian akan dilanjutkan oleh mikrokontroler menuju ke raspberry pi untuk diproses didalam raspberry pi lalu akan dikembalikan lagi ke mikrokontroler berupa perintah untuk melakukan eksekusi. Keluaran yang diberikan berupa perintah untuk membuka pintu rumah lalu menyalakan lampu dari setiap ruangan yang ada dirumah berdasarkan seberapa jauh jarak dari pengguna dengan rumah, lalu apakah pengguna bergerak mendekati rumah atau hanya berdiam diri saja selain itu juga ketika pengguna sudah semakin dekat ditandai dengan adanya tekanan yang diberikan pengguna rumah ketika menginjak sensor tekanan yang berada tepat didepan pintu. Mematikan lampu dan menutup pintu ketika teridentifikasi sudah tidak adanya pergerakan dan adanya tekanan yang diberikan pada sensor tekanan yang terletak di dalam ruangan. Rancangan dari sistem smart home dapat dilihat pada Gambar 2.

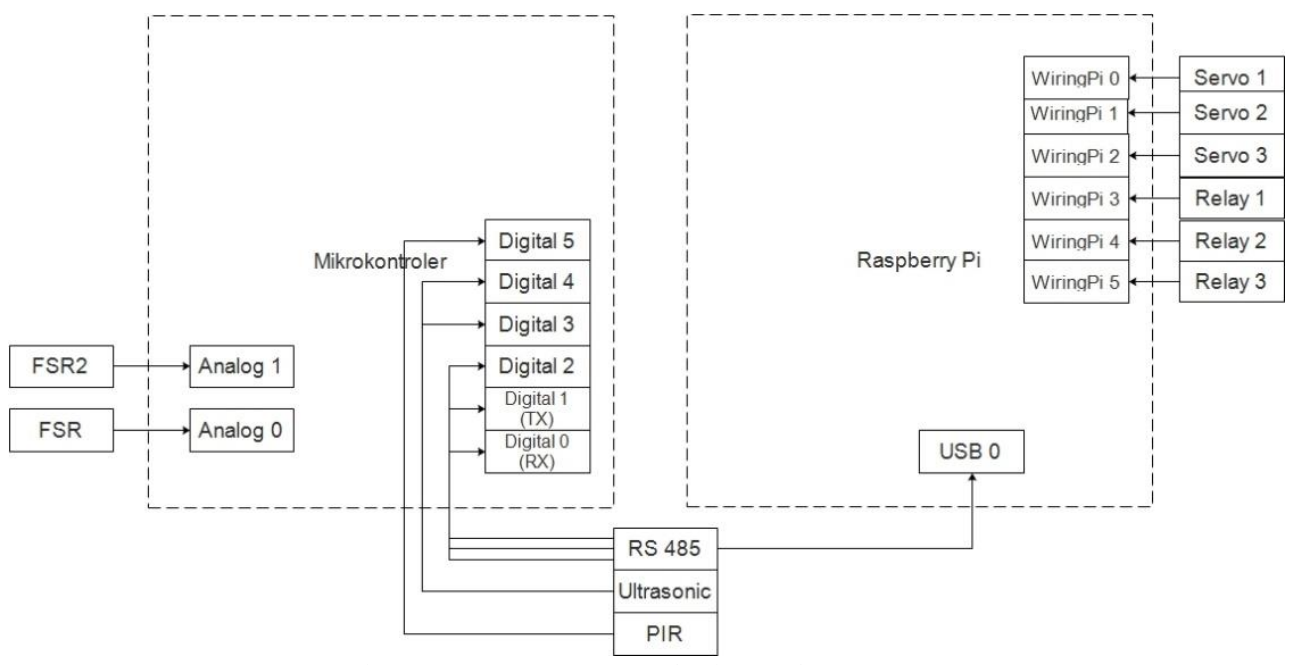

Gambar 1 Rancangan arsitektur sistem

\subsection{Rancangan elektronik}

Komponen yang digunakan dalam penelitian ini disambungkan dengan mikrokontroler ATMega328P. Mikrokontroler ATMega328P yang digunakan sudah dalam bentuk modul dengan pin yang dapat digunakan untuk kebutuhan yang spesifik.

Sensor ultrasonik yang digunakan pada penelitian ini adalah HY-SRF05. Sensor ini digunakan untuk membaca jarak ketika pengguna mendekat kearah rumah. Sensor Passive Infrared Receiver (PIR) yang digunakan adalah HC-SR501. Sensor HC-SR501 digunakan untuk mendeteksi pergerakan yang ada didepan ruangan. Sensor tekanan yang digunakan adalah Force Sensitive Resistor (FSR). Sensor FSR digunakan untuk mengukur tekanan yang diberikan oleh 
pengguna ketika berada didepan rumah atau lebih tepatnya ketika berada didepan pintu garasi. Komunikasi serial dibutuhkan untuk mengirim dan menerima perintah dari Raspberry pi. Tiga pin PWM digunakan untuk masukan motor. Motor yang digunakan pada penelitian ini adalah Micro Servo SG90. Mikro Servo SG90 digunakan sebagai penggerak pintu ketika membuka ataupun menutup. Output yang digunakan lagi selain itu ada lampu bohlam yang dihubungkan dengan relay. Relay yang digunakan pada penelitian ini modul relay 5 volt. Fungsi dari relay pada penelitian ini sebagai saklar otomatis untuk lampu bohlam. Detail rancangan penggunaan pin terdapat pada Tabel 1 .

Tabel 1 Rancangan pin mikrokontroler

\begin{tabular}{|l|l|l|}
\hline No & \multicolumn{1}{|c|}{ Pin } & \multicolumn{1}{c|}{ Keterangan } \\
\hline 1 & Digital 0 & Pin Serial RX RS-485 \\
\hline 2 & Digital 1 & Pin Serial TX RS-485 \\
\hline 3 & Digital 2 & Pin Digital RS-485 \\
\hline 4 & Digital 3 & Pin Digital Trigger HY-SRF05 \\
\hline 5 & Digital 4 & Pin Digital Echo HY-SRF05 \\
\hline 6 & Digital 5 & Pin Digital PIR \\
\hline 7 & A0 & Pin Analog Untuk Sensor FSR \\
\hline 8 & A1 & Pin Analog Untuk Sensor FSR kedua \\
\hline
\end{tabular}

\subsection{Perancangan perangkat lunak}

Perancangan perangkat lunak bertujuan untuk membuat instruksi pada sistem sehingga dapat sistem bekerja sesuai dengan yang diinginkan. Perancangan algoritma meliputi deklarasi variabel, pembacaan, akses sensor dan eksekusi pada aktuator maupun perangkat lainnya. Algoritma menggunakan unit pengolahan mikrokontroler arduino dengan bahasa pemrograman $\mathrm{C}$ menggunakan arduino IDE sebagai compiler-nya dan menggunakan juga unit komputer papan tunggal (single-board circuit) raspberry pi dengan menggunakan bahasa pemrograman yang sama dengan arduino, tetapi sebagai compiler-nya menggunakan WiringPi. Tujuan utama dari perancangan perangkat lunak ini adalah membaca nilai bacaan dari sensor dan memberikan instruksi sehingga sistem smart home bisa menjalankan skenario sesuai dengan yang diinginkan. Diagram alir program tersebut ditunjukkan pada Gambar 2 .

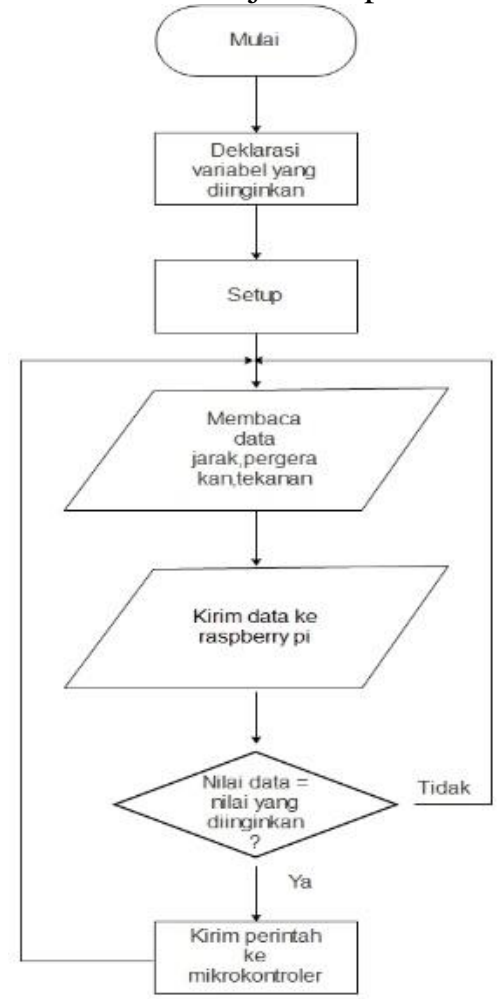

Gambar 2 Diagram alir program keseluruhan algoritma 


\subsection{Rancang bangun}

Agar memiliki kesamaan dengan bentuk rumah pada ukuran yang sesungguhnya maka penelitian ini menggunakan bahan acrylic yang dibentuk seperti halnya rumah pada umumnya menggunakan tiga ruangan sebagai perwujudan dari sistem smarthome. Penggunaan bahan acrylic dipilih karena merupakan bahan yang cukup kuat sehingga tidak mudah rusak dan bahan ini dapat didesain sesuai dengan yang diinginkan. Terlebih lagi pada penelitian ini terdapat 3 buah bentuk pintu yang memerlukan engsel seperti pada pintu umumnya maka acrylic harus didesain menjadi engsel untuk pintu pada rancang bangun ini.

Purwarupa bangunan rumah ini dirancangan memiliki 3 buah ruangan dengan setiap ruangannya memiliki ukuran yang sama yaitu $20 \times 30 \mathrm{~cm}$. Maka total luas dari bangunan ini adalah $40 \times 30 \mathrm{~cm}^{2}$. Tiga buah ruangan tersebut perwujudan dari ruang tamu, ruang kamar dan juga garasi. Rancangan denah detail dari smart home dapat dilihat pada Gambar 3.

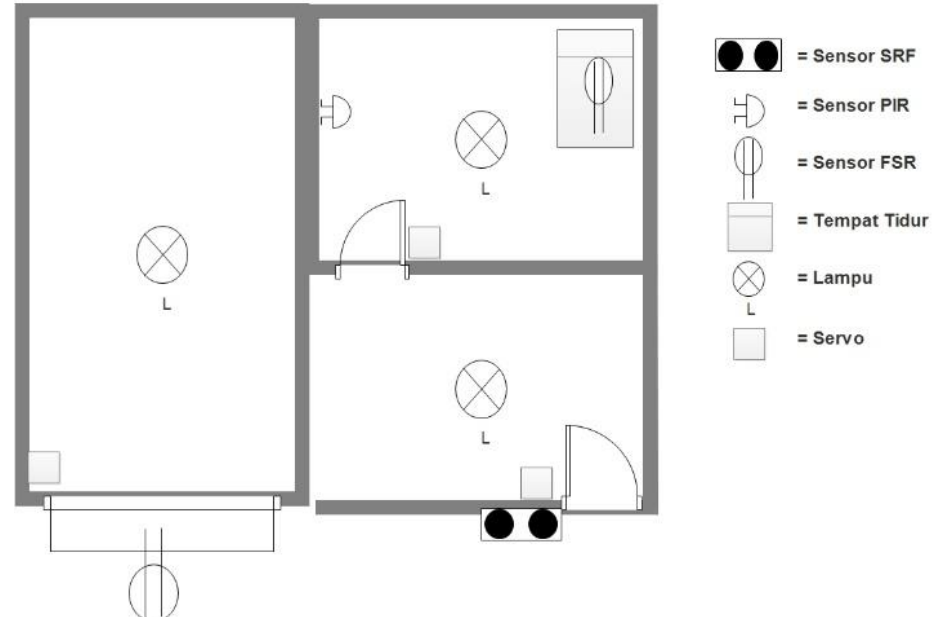

Gambar 3 Denah rancang bangun

\section{HASIL DAN PEMBAHASAN}

\subsection{Hasil perancangan ontology}

Dalam proses perancangan rancangan ontology pada penelitian ini menggunakan aplikasi protégé seperti pada penelitian yang sudah ada sebelumnya $[6,7,8]$. Perancangan ontology membutuhkan tool atau alat bantu yang yang sesuai dengan kebutuhan. Penelitian ini menggunakan aplikasi Protégé untuk membantu dalam perancangan OWL. Protégé adalah perangkat lunak bantu yang digunakan untuk pengembangan sistem berikut Knowledge Base System [9]. Membuat class dan sub class sebagai rancangan awal dari ontology agar mempermudah proses pembuatan skema ontology. Rancangan awal ini hanya memiliki hubungan class utama dengan sub class nya saja tidak ada penjelasan atau pengertian seca lebih detail lagi, sehingga belum dapat digunakan sebagai informasi yang utuh. Pada proses yang selanjutnya akan ditambahkan informasi yang lebih detail lagi agar rancangan ontology ini memiliki informasi yang lengkap dan dapat digunakan . Seperti pada Gambar 4 menunjukkan skema ontology dengan context sebagai class utama dan sub class nya tanpa ada informasi yang lebih lengkap. Maka agar rancangan ontology memiliki informasi yang lengkap dan dapat di implementasikan menjadi sistem smart home maka perlu ditambahkan beberapa informasi yang digunakan pada penelitian ini seperti property dan instance atau individu [10]. Protégé dibuat dengan menggunakan bahasa pemrograman Java, dengan semua alat-alat dalam aplikasi protégé dapat digunakan melalui Graphical User Interface (GUI) dengan menyediakan Tab untuk masing-masing bagian dan fungsinya [7]. 


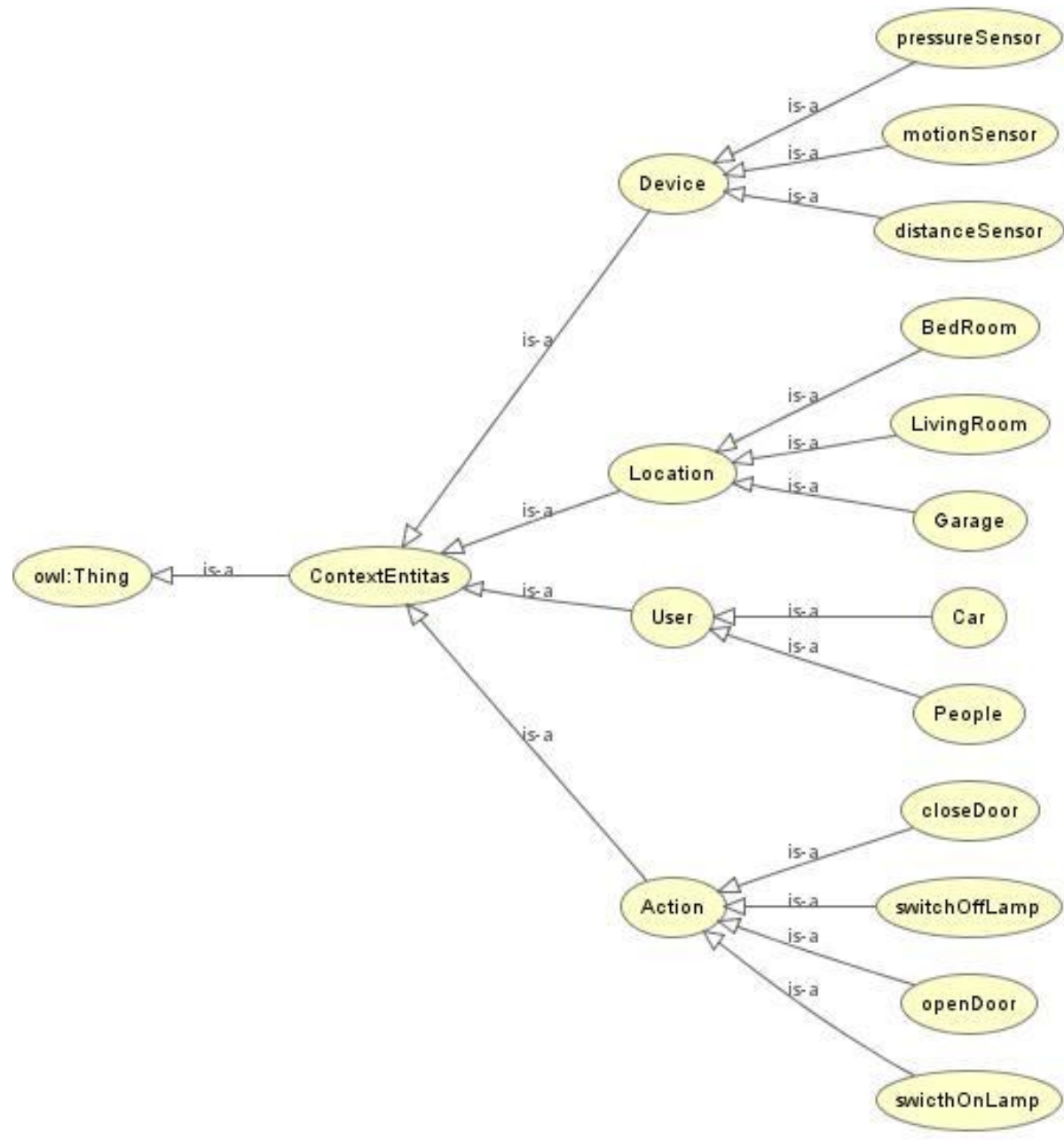

Gambar 4 Rancangan awal ontology

\subsection{Hasil pengujian dengan skenario}

Pada tahapan pengujian ini dibagi menjadi 3 skenario sesuai dengan rancangan owl yang sudah lengkap dengan semua informasi yang dibutuhkan untuk dapat diimplementasikan. Setiap skenario ini adalah bentuk implementasi dari ontology yang diterapkan pada smart home dengan 4 context yang menjadi class utama. Setiap class utama masih memiliki masing-masing subclass lagi yang nantinya akan menjadi rangkaian proses dari setiap skenario. Dapat ditentukannya skenario juga berdasar hasil dari ontology yang sudah lengkap dengan class, subclass, object property dan instance atau properties.

\subsubsection{Skenario ketika penghuni datang}

Pengujian skenario yang pertama adalah ketika penghuni datang maka sensor srf akan membaca jarak antara orang yang berjalan mendekati rumah lalu ketika sudah mencapai jarak yang ingin dicapai maka pintu akan membuka secara otomatis dan lampu pada ruang tengah dan kamar akan menyala. Sebelumnya ontology yang sudah dirancang tadi akan dilengkapi dengan instance dan property agar dapat di implementasikan pada purwarupa sistem smart home.

Hasil ontology akan dilengkapi dengan property dan instance setelah itu rancangan ontology diterapkan pada sebuah skenario pada sistem smart home yang sesuai dengan hasil dari rancangan ontology seperti yang terdapat pada Gambar 5. 


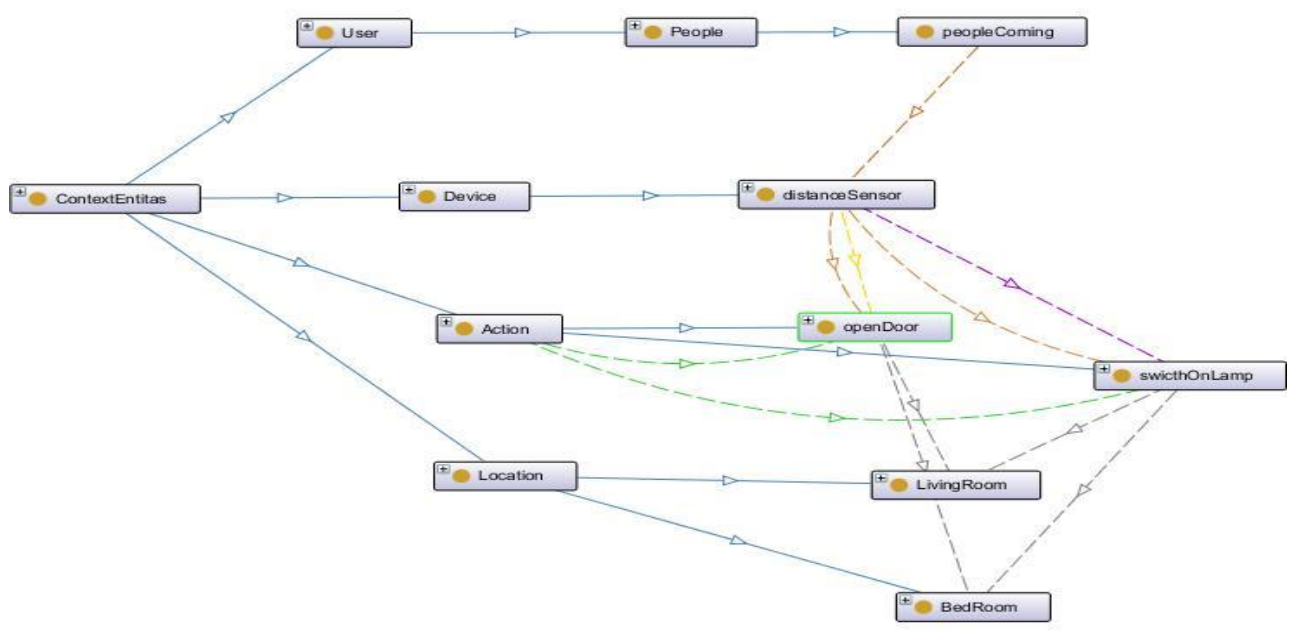

Gambar 5 Ontology skenario ketika penghuni datang

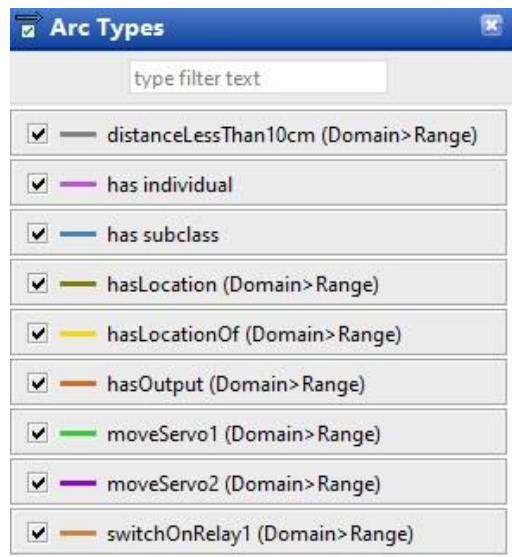

Gambar 6 Keterangan property

Tabel 2 Pengujian skenario penghuni datang

\begin{tabular}{|c|c|c|c|c|}
\hline \multirow{2}{*}{$\begin{array}{c}\text { Jarak } \\
(\mathrm{cm})\end{array}$} & \multicolumn{4}{|c|}{ Kondisi } \\
\cline { 2 - 5 } & $\begin{array}{c}\text { Pintu } \\
\text { Depan }\end{array}$ & $\begin{array}{c}\text { Lampu } \\
\text { Depan }\end{array}$ & $\begin{array}{c}\text { Pintu } \\
\text { Kamar }\end{array}$ & $\begin{array}{c}\text { Lampu } \\
\text { Kamar }\end{array}$ \\
\hline 15 & Tertutup & Mati & Tertutup & Mati \\
\hline 14 & Tertutup & Mati & Tertutup & Mati \\
\hline 13 & Tertutup & Mati & Tertutup & Mati \\
\hline 12 & Tertutup & Mati & Tertutup & Mati \\
\hline 11 & Tertutup & Mati & Tertutup & Mati \\
\hline 10 & Terbuka & Menyala & Terbuka & Menyala \\
\hline 9 & Terbuka & Menyala & Terbuka & Menyala \\
\hline 8 & Terbuka & Menyala & Terbuka & Menyala \\
\hline 7 & Terbuka & Menyala & Terbuka & Menyala \\
\hline 6 & Terbuka & Menyala & Terbuka & Menyala \\
\hline 5 & Terbuka & Menyala & Terbuka & Menyala \\
\hline 4 & Terbuka & Menyala & Terbuka & Menyala \\
\hline 3 & Terbuka & Menyala & Terbuka & Menyala \\
\hline
\end{tabular}


Pada Gambar 5 enunjukkan setiap property dari setiap class, menjelaskan hubungan dari masing-masing class dan pada Gambar 6 terdapat keterangan dari semua property yang ada. Pada Tabel 2 menunjukkan hasil dari pengujian sistem smart home hasil dari implementasi rancangan ontology dengan nilai acuan yang sama dengan yang ada pada rancangan ontology pada Gambar 5.

\subsubsection{Skenario ketika mobil datang}

Hasil ontology akan dilengkapi dengan property dan instance setelah itu rancangan ontology diterapkan pada sebuah skenario yang sesuai dengan hasil dari rancangan ontology seperti yang terdapat pada Gambar 7 dan Gambar 6 merupakan keterangan property.

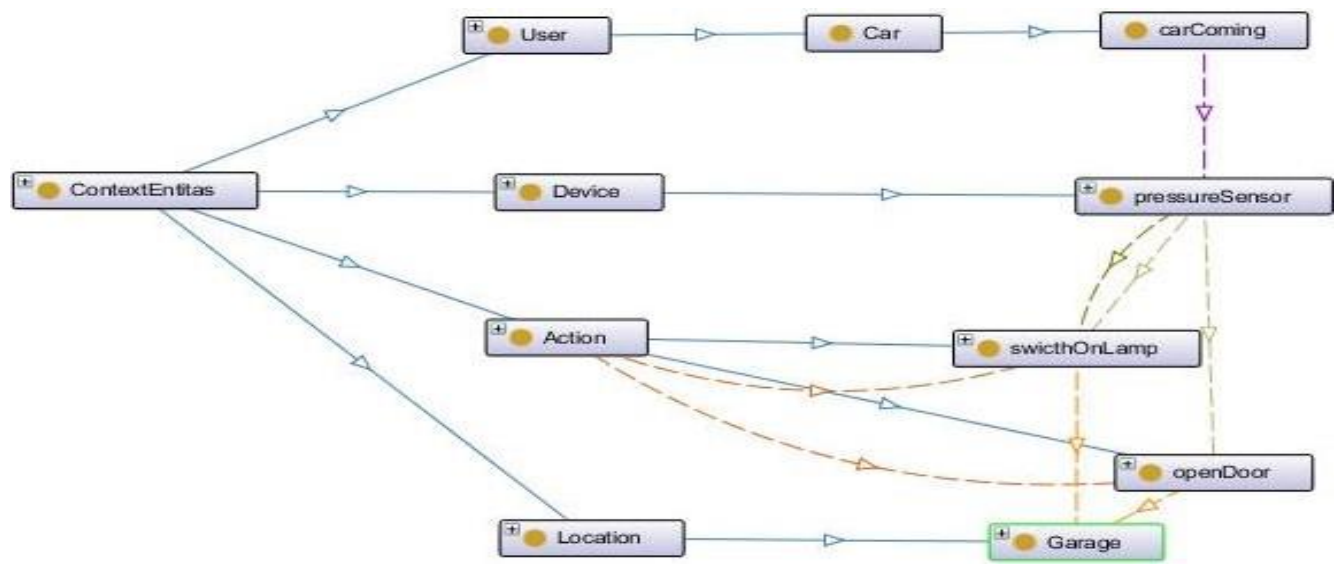

Gambar 7 Ontology scenario mobil datang

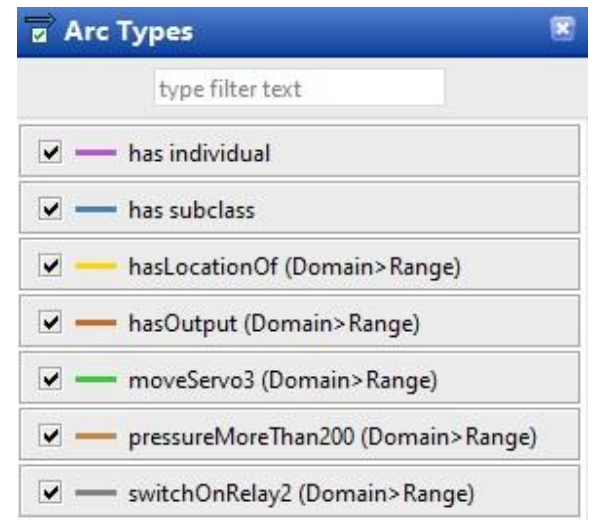

Gambar 8 Keterangan property ontology

Tabel 3 Hasil pengujian scenario mobil datang

\begin{tabular}{|c|c|c|}
\hline $\begin{array}{c}\text { Tekanan } \\
\text { Mobil }\end{array}$ & $\begin{array}{c}\text { Kondisi } \\
\text { Pintu }\end{array}$ & $\begin{array}{c}\text { Kondisi } \\
\text { Lampu }\end{array}$ \\
\hline 158 & Tertutup & Mati \\
\hline 197 & Tertutup & Mati \\
\hline 251 & Terbuka & Menyala \\
\hline
\end{tabular}


Setelah dapat diimplementasikan pada skenario maka dilakukan pengujian apakah sistem smart home yang dibuat sudah sesuai dengan rancangan ontology. Pada Tabel 3 menunjukkan pengujian scenario ketika mobil datang dengan menggunakan sensor fsr atau sensor tekanan dengan nilai acuan lebih dari 200 maka pintu akan terbuka melalui bantuan servo dan lampu akan menyala.

\subsubsection{Skenario ketika penghuni sedang tidur}

Hasil ontology akan dilengkapi dengan property dan instance setelah itu rancangan ontology diterapkan pada sebuah skenario yang sesuai dengan hasil dari rancangan ontology seperti yang terdapat pada Gambar 7 dan Gambar 6 merupakan keterangan property.

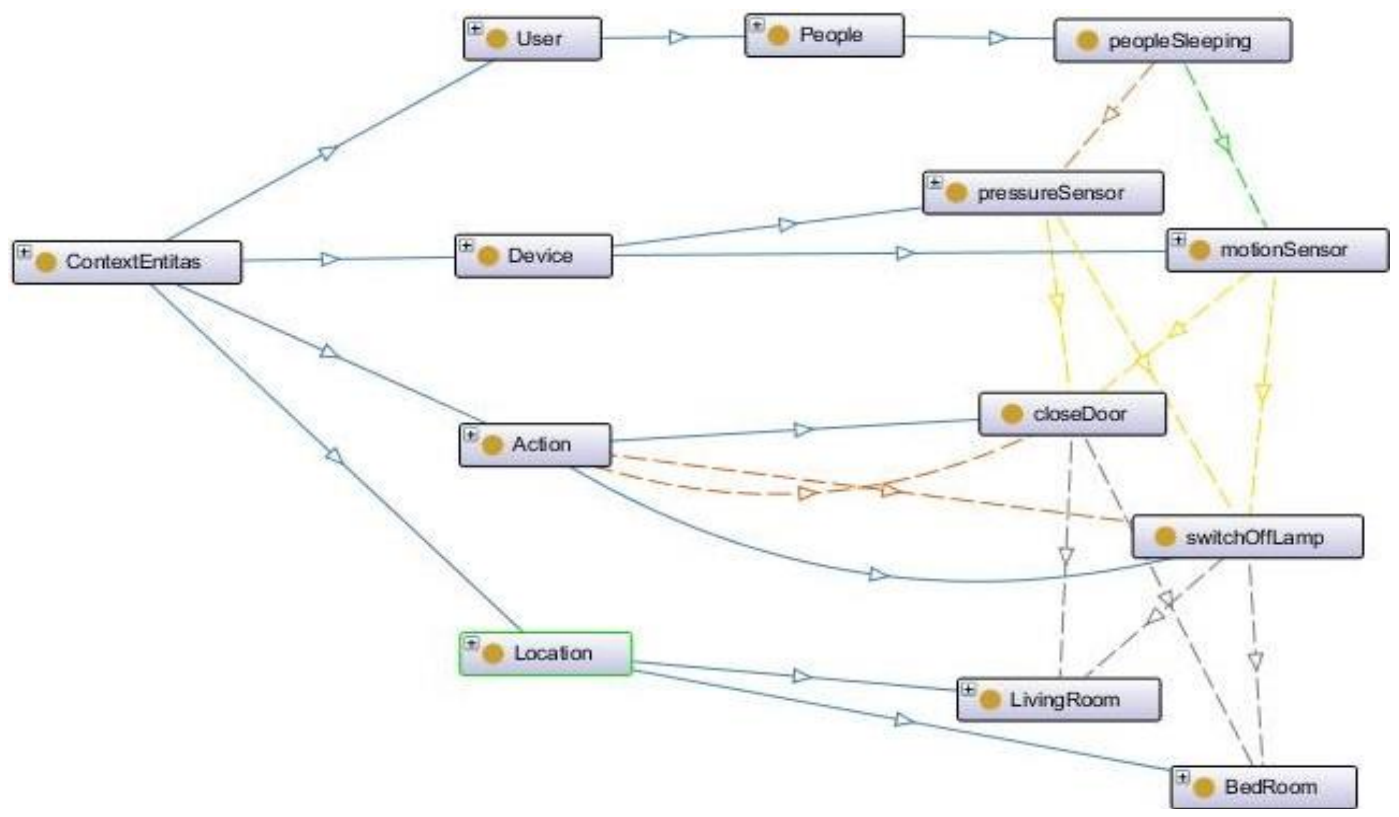

Gambar 9 Ontology skenario ketika penghuni sedang tidur

\begin{tabular}{|c|}
\hline$\checkmark-$ has individual \\
\hline$\checkmark-$ has subclass \\
\hline$\checkmark-$ hasLocationln (Domain $>$ Range) \\
\hline$\checkmark-$ hasOutput (Domain $>$ Range) \\
\hline$\checkmark-$ noMotion (Domain $>$ Range) \\
\hline$\checkmark-$ pressureMoreThen100 (Domain $>$ Range) \\
\hline$\checkmark-$ switchOff (Domain $>$ Range) \\
\hline \hline
\end{tabular}

Gambar 10 Keterangan property 
Tabel 4 Hasil pengujian ketika penghuni sedang tidur

\begin{tabular}{|c|c|c|c|}
\hline Pergerakan & Tekanan & $\begin{array}{c}\text { Kondisi } \\
\text { Pintu }\end{array}$ & $\begin{array}{c}\text { Kondisi } \\
\text { Lampu }\end{array}$ \\
\hline 1 & 0 & Terbuka & Menyala \\
\hline 1 & 100 & Terbuka & Menyala \\
\hline 0 & 0 & Terbuka & Menyala \\
\hline 0 & 100 & Tertutup & Mati \\
\hline
\end{tabular}

Setelah dapat diimplementasikan pada skenario maka dilakukan pengujian apakah sistem smart home yang dibuat sudah sesuai dengan rancangan ontology. Pada Tabel 4 menunjukkan pengujian skenario ketika penghuni sedang tidur dengan menggunakan sensor fsr atau sensor tekanan dengan nilai acuan lebih dari 100 dan sensor pir atau sensor pergerakan sehingga ketika sensor pir membaca tidak ada pergerakan di area tempat tidur atau nilai bacaan dari sensor 0 maka pintu kamar tidur yang tadinya masih terbuka akan tertutup melalui bantuan servo dan lampu pada kamar tidur serta lampu ruang tengah yang terhubung dengan relay yang sama dengan kondisi awal menyala maka akan mati.

\section{KESIMPULAN}

Dengan telah dilakukan penelitian ini maka dapat disimpulkan bahwa metode ontology dapat diterapkan pada sistem smart home yang berbasis context aware. Context dari sistem smart home dijadikan sebagai class utama pada skema ontology dan dapat di implementasikan pada sistem smart home. Pengujian dengan menggunakan skenario juga dapat memeperkuat bahwa context aware tidak dapat berdiri sendiri maka perlu di bantu dengan metode yang lain dan salah satu metode tersebut adalah ontology.

\section{SARAN}

Saran yang dapat digunakan untuk mengembangkan peneltian selanjutnya yaitu coba penerapan bahasa ontology pada web-based karena pada penelitian ini penerapan bahasa ontologynya masih sebatas konvensional saja. Diharapkan jika diterapkan pada web-based akan menambah banyak informasi yang dibutuhkan pada sebuah sistem.

\section{DAFTAR PUSTAKA}

[1] F. Behmann dan K. Wu, "Application Requirements," in Collaborative Internet of Things (C-IoT):for Future Smart Connected Life and Business, 2015.

[2] K. Wongpatikaseree, M. Ikeda, M. Buranarach, T. Supnithi, A. O. Lim, dan Y. Tan, "Activity recognition using context-aware infrastructure ontology in smart home domain,” Proc. - 2012 7th Int. Conf. Knowledge, Inf. Creat. Support Syst. KICSS 2012, hal. 50-57, 2012.

[3] J. Zhao dan L. Lü, "Smart home model based on ontology and context-awareness," 2008 IEEE Int. Conf. Granul. Comput., hal. 830-833, 2008.

[4] A. Dewabharata, D. M. H. Wen, dan S. Y. Chou, "An activity ontology for context-

Penggunaan Metode Ontology untuk Perancangan Purwarupa Sistem ... (Guntur Perdana) 
aware health promotion application," Proc. - Int. Comput. Softw. Appl. Conf., hal. 421426, 2013.

[5] A. Patel dan T. A. Champaneria, "Fuzzy logic based algorithm for Context Awareness in IoT for Smart home environment," 2016 IEEE Reg. 10 Conf., hal. 1057-1060, 2016.

[6] Q. Ni, A. B. García Hernando, dan I. P. De La Cruz, "A Context-Aware System Infrastructure for Monitoring Activities of Daily Living in Smart Home," J. Sensors, vol. 2016, 2016.

[7] Y. F. Badron, F. Agus, dan H. R. Hatta, "STUDI TENTANG PEMODELAN ONTOLOGI WEB SEMANTIK ARTIKEL JURNAL ILMIAH," vol. 2, no. 1, 2017.

[8] L. E. Nugroho, L. Lazuardi, dan K. Non-alinsavath, "Ontology-based Context Aware for Ubiquitous Home Care for Elderly People," Proc. 2015 2nd Int. Conf. Inf. Technol. Comput. Electr. Eng. (ICITACEE), Indones. Oct 16-18th, hal. 454-459, 2015.

[9] H. Guermah, T. Fissaa, H. Hafiddi, M. Nassar, dan A. Kriouile, "An Ontology Oriented Architecture for Context Aware Services Adaptation," vol. 11har, no. 2, hal. 24-33, 2014.

[10] Y. Wu dan G. Bao, "A method of semantic annotation and ontology construction for unified command and control language," Proc. - 2013 10th Web Inf. Syst. Appl. Conf. WISA 2013, hal. 415-418, 2013. 